\title{
Behavioral responses of predaceous minute pirate bugs to tridecane, a volatile emitted by the brown marmorated stink bug
}

\author{
Diego F. Fraga ${ }^{1,2}$ (D) Joyce Parker ${ }^{3}$ Antonio C. Busoli ${ }^{2}$ George C. Hamilton ${ }^{1}$ • \\ Anne L. Nielsen ${ }^{1} \cdot$ Cesar Rodriguez-Saona ${ }^{1}$
}

Received: 29 June 2016/Revised: 18 November 2016/Accepted: 29 November 2016/Published online: 27 December 2016

(c) Springer-Verlag Berlin Heidelberg 2016

\begin{abstract}
Since its introduction from Asia, the brown marmorated stink bug, Halyomorpha halys (Stål), has become a pest of many agricultural crops in the USA. Insect predators utilize $H$. halys as prey; however, the chemical cues used by them in prey location are largely unknown. Here, we hypothesized that tridecane, an $H$. halys-associated volatile, acts as a kairomone for the predaceous minute pirate bug, Orius insidiosus (Say). We conducted laboratory, greenhouse, and field experiments to: (1) assess the attraction of adult $O$. insidiosus to $H$. halys-damaged bean pods and tridecane in cage studies, and its effect on egg predation; (2) video record the behavioral response of $O$. insidiosus males and females to tridecane in a four-arm olfactometer; and (3) test whether Orius spp. are attracted to tridecane-baited sticky traps in peach, blueberry, and sunflower fields, and its effect on egg predation. In the greenhouse, $O$. insidiosus was attracted to $H$. halys-damaged pods and artificial plants baited with tridecane in the presence of prey (sentinel eggs); however, this attraction rarely led to increased egg predation. Although both $O$.
\end{abstract}

Communicated by T. Haye.

Special Issue: The brown marmorated stink bug Halyomorpha halys an emerging pest of global concern.

Diego F. Fraga

diegoffraga@gmail.com

1 Department of Entomology, Rutgers University, 96 Lipman Drive, New Brunswick, NJ 08901, USA

2 Departamento de Fitossanidade, UNESP/FCAV, km 5 Via de Acesso Professor Paulo Donato Castellane, Jaboticabal, SP 14884-900, Brazil

3 United States Department of Agriculture, National Institute of Food and Agriculture, 1400 Independence Ave., Washington, DC 20250, USA insidiosus males and females spent more time in the arm of the olfactometer with tridecane, males were more responsive at a lower concentration than females. Similarly, Orius spp. were more attracted to tridecane-baited than unbaited traps in the field; however, there was no effect on egg predation. Altogether, while $O$. insidiosus is attracted to tridecane, this attraction did not always lead to higher predation, suggesting that this kairomone likely acts as an arrestant.

Keywords Orius insidiosus · Halyomorpha halys . BMSB - Conservative biological control - Invasive pests · Kairomones

\section{Key message}

- We tested the hypothesis that the predator Orius insidiosus utilizes volatiles associated with Halyomorpha halys during prey location.

- Orius insidiosus spent more time foraging on bean plants damaged by $H$. halys in the presence of prey.

- Tridecane was a major compound emitted by $H$. halys and $H$. halys-damaged plants.

- Laboratory, greenhouse, and field experiments showed attraction of $O$. insidiosus to tridecane.

- An increased attraction to tridecane by $O$. insidiosus did not always enhance predation.

- Tridecane arrested $O$. insidiosus foraging behavior.

\section{Introduction}

As proposed by the enemy release hypothesis, invasive pests usually impose a major challenge to integrated pest management (IPM) programs because they often arrive to a 
new territory free from their natural enemies (Keane and Crawley 2002; Colautti et al. 2004; Pimentel et al. 2005). Natural enemies in the invaded territories are rarely adapted to utilize these novel food items; therefore, it may take several years until they are able to regulate the pests' populations (e.g., Chabaane et al. 2015). A possible reason is that native natural enemies do not usually recognize the chemicals emitted from these invasive pests (i.e., kairomones) and are consequently unable to locate them (Desurmont et al. 2014). Thus, identifying and understanding the response of natural enemies to volatiles emitted by invasive pests is critical for their conservation and augmentative releases in agro-ecosystems.

Natural enemies of herbivorous insects, i.e., predators and parasitoids, are known to use chemical cues to find their host/prey (Turlings et al. 1990). Such cues involve volatiles either emitted by plants in response to insect damage or emitted by the herbivores themselves (Ninkovic et al. 2001; De Boer and Dicke 2004; Van Den Boom et al. 2004; Zhu and Park 2005). In fact, natural enemies can be attracted to specific volatile compounds, or even to specific ratios of volatiles within blends, produced by their host (De Moraes et al. 1998; Reddy et al. 2002; Colazza et al. 2014). These volatiles, once identified, can be used to attract natural enemies into agro-ecosystems (Khan et al. 2008; Rodriguez-Saona et al. 2012; Kelly et al. 2014). For example, methyl salicylate (MeSA), a volatile commonly emitted by plants after herbivore damage (also known as herbivore-induced plant volatiles, HIPVs), has been reported to elicit behavioral responses in several groups of insect predators of agricultural pests (James and Price 2004; Rodriguez-Saona et al. 2011; Gadino et al. 2012; Kelly et al. 2014).

Halyomorpha halys (Stål) (Hemiptera: Pentatomidae), commonly referred to as brown marmorated stink bug (BMSB), is an invasive pest introduced into the USA (USA) from Asia (Leskey et al. 2012a; Xu et al. 2014). It was originally detected in Allentown, Pennsylvania (USA), in 1996 (Hoebeke and Carter 2003), and since then it has been reported and intercepted in 42 states (Northeastern IPM Center 2016). Halyomorpha halys has a large host range (Nielsen and Hamilton 2009; Northeastern IPM Center 2016) and, since its introduction in the USA, it has caused more than $\$ 37$ million in losses to apples (Leskey et al. 2012b), as well as substantial economic losses to other crops such as ornamentals, vegetables, and field crops (Kuhar et al. 2012). Due to H. halys, insecticide use has increased in many cropping systems (Leskey et al. 2012a, b). Alternative management strategies such as conservation biological control have not yet been implemented, although studies with native natural enemies of $H$. halys have been initiated in the USA (Rice et al. 2014; Morrison et al. 2016). Insect predators can play an important role in $H$. halys control in vegetables, ornamentals, tree fruit, and field and organic crops (Leskey et al. 2012a). Leskey et al. (2012a) reported generalist predators in the Chrysopidae, Reduviidae, Lygaidae, and Anthocoridae families using $H$. halys as prey. However, the chemical cues used by natural enemies to locate $H$. halys remain unknown.

Minute pirate bugs (Orius spp.) (Hemiptera: Anthocoridae) have been observed feeding on $H$. halys egg masses (Biddinger et al. 2012; Morrison et al. 2016). One of its members, Orius insidiosus (Say), is widespread throughout the USA (Shipp and Ramakers 2004) and is a well-known predator of thrips, aphids, mites, and eggs and young larvae of various agricultural pests (Iglinsky and Rainwater 1950; Hansen et al. 2003; Osekre et al. 2008; Harwood et al. 2009). Orius spp. and other anthocorids frequently exploit host-plant and prey-associated odors, also known as kairomones, to guide them during foraging (Reid and Lampman 1989; Lattin 1990; Aldrich et al. 2007). For example, Teerling et al. (1993) demonstrated that Orius tristicolor (White) searches more intensively in the presence of the alarm pheromone (decyl and dodecyl acetates) of its prey the western flower thrips, Frankliniella occidentalis (Pergande). Additionally, O. tristicolor and Orius similis Zheng are attracted to sticky traps baited with MeSA in hop yards (James 2005) and cotton fields (Yu et al. 2008).

In the present study, we tested the hypothesis that $O$. insidiosus utilizes volatiles associated with $H$. halys during prey location. Specifically, we conducted a series of laboratory, greenhouse, and field experiments to: (1) determine the behavioral response of $O$. insidiosus to beans damaged by $H$. halys in greenhouse cages, and evaluate the effects of this response on egg predation; (2) isolate and identify the volatiles emitted from $H$. halys nymphs and adults, and from $H$. halys-bean associations; (3) test the behavioral response of $O$. insidiosus to the major volatile emitted from $H$. halys (tridecane) in cage studies and under field conditions (blueberries, peaches, and sunflower); and (4) examine in more detail, using an olfactometer and video recordings, the effects of tridecane on $O$. insidiosus foraging behavior.

\section{Materials and methods}

\section{Insects}

A laboratory colony of $H$. halys was sourced from a colony maintained at the Rutgers Agricultural Research and Extension Center (RAREC; Bridgeton, NJ, USA) and from adults collected in May 2014 from peach orchard in Bridgeton, NJ. The colony was kept in insect rearing cages 
$(30 \times 30 \times 30 \mathrm{~cm} ;$ Bugdorm Insect Cage; MegaView Science Co Ltd, Taichung, Taiwan). Halyomorpha halys was fed with organic carrots, apples, broad bean pods, and sunflower seeds; food was changed every two days, and water was provided with soaked cotton wool in small containers $(50 \mathrm{ml})$. Paper towels were placed inside each cage as oviposition substrate. Orius insidiosus adults for olfactometer and greenhouse experiments were obtained from Rincon-Vitova Insectaries (Ventura, CA, USA) and sexed as described by Herring (1966). Both insect colonies were maintained in an environmental chamber kept at $25 \pm 1{ }^{\circ} \mathrm{C}, 50 \pm 10 \% \mathrm{RH}$, and 14L:10D.

For greenhouse experiments and volatile collections, $H$. halys adults and nymphs were separated from the colony and starved for $24 \mathrm{~h}$ prior to being placed on experimental plants. For cage and olfactometer experiments, individual $O$. insidiosus adults were placed in smaller plastic containers and deprived of food overnight until the start of the bioassays. In order to assess predation in the greenhouse and field experiments, egg masses of the European corn borer, Ostrinia nubilalis (Hübner) (Lepidoptera: Crambidae), were used due to their commercial availability (Rincon-Vitova Insectaries) and also because they are commonly used by $O$. insidiosus as prey in nature (Andow 1990; Musser and Shelton 2003).

\section{Plants}

For volatile collections and to assess $O$. insidiosus attraction to $H$. halys-damaged plants, common bean plants (Phaseolus vulgaris L.) (Burpee; Warminster, PA, USA) were used due to their fast growth and because bean pods are a suitable food source for $H$. halys. Seeds of beans were sown in pots filled with standard potting mix with new plants being sowed at 2-week intervals. Plants were kept in a greenhouse at the Rutgers P.E. Marucci Center (Chatsworth, NJ, USA), at $26 \pm 1{ }^{\circ} \mathrm{C}, 50 \pm 10 \% \mathrm{RH}$, and 14L:10D. Plants were used when pods were fully developed (approximately 4-5 weeks after seeding), watered three times a week or more often if needed, and fertilized biweekly with PRO-SOL 20-20-20N-P-K All Purpose Plant Food (Pro Sol Inc; Ozark, AL, USA) (each plant received approximately $100 \mathrm{ml}$ of a $2 \mathrm{~g}$ of fertilizer per liter of water solution).

\section{Behavioral response of predators to infested plants}

We conducted an experiment in the greenhouse to investigate the attraction of $O$. insidiosus to volatiles emitted from bean pods damaged by $H$. halys and whether this attraction leads to increased predation of $O$. nubilalis eggs. Our treatments consisted of: (1) $H$. halys-damaged plants (pods) with prey (i.e., eggs); (2) H. halys-damaged plants with no prey; (3) undamaged plants with prey; and (4) undamaged plants with no prey. For the damage treatments, five $H$. halys adults were kept with bean pods inside closed white organza bags (Uline; Pleasant Prairie, WI, USA) for $72 \mathrm{~h}$. Bags and insects were removed prior to the choice tests (see below). For the treatments with prey, four pieces of wax paper each containing an individual $O$. nubilalis egg mass (each egg mass had approximately 25 eggs) were glued to a green plastic card; the card was then pinned to the underside of one of the fully matured leaves-one card per plant.

For each choice test, four plants (two of each treatment) were placed in cages $(60 \times 60 \times 60 \mathrm{~cm}$; Bugdorm Insect Cage; MegaView Science Co Ltd), equidistant from each other, and with plants treated in the same manner placed diagonal from each other. Ten $O$. insidiosus adults (mixed sexes) were released in the morning $(10: 00 \mathrm{~h})$ inside each cage (center), and their position was recorded every hour for $6 \mathrm{~h}$ (i.e., total of six times per day from 10:00 to 14:00 h) for 2 days. To measure egg predation, the numbers of $O$. nubilalis eggs per mass were counted before and after each experiment; eggs were examined under the microscope for signs of predation by piercing and sucking. Each choice test was replicated four times.

\section{Volatile collection and analysis}

We collected volatile organic compounds (VOCs) emitted from $H$. halys-damaged bean pods, $H$. halys nymphs and adults, and mechanically damaged bean pods in the greenhouse $\left(26 \pm 1{ }^{\circ} \mathrm{C}, 50 \pm 10 \% \mathrm{RH}\right.$, and $\left.14 \mathrm{~L}: 10 \mathrm{D}\right)$, using a pull system (Tholl and Röse 2006). Individual fully developed bean pods were covered with organza bags. Treatments consisted of bean pods with $5 \mathrm{H}$. halys adults or nymphs (3rd-5th instar) inside the bags; 5 H. halys nymphs only; $5 \mathrm{H}$. halys adults only; mechanically damaged bean pods; bean pods only; and empty bags (blank controls). Insects were allowed to feed on the pods for 2-3 days and then removed prior to volatile collections. Mechanical damage consisted of 20 sequential pokes (10 pokes per day for 2 days) on each pod using sharpened forceps. Each treatment was repeated 3-6 times.

Volatiles from inside the bags were collected on $30 \mathrm{mg}$ Super-Q adsorbent traps (Alltech; Deerfield, IL, USA) by pulling air at a rate of $300 \mathrm{ml} \mathrm{min}{ }^{-1}$ with the aid of microdiaphragm air pumps (Sensidyne; Saint Petersburg, FL, USA). Prior to each collection, traps were cleaned by rinsing them three times with $5 \mathrm{ml}$ of dichloromethane (99\% purity; Sigma-Aldrich; St. Louis, MO, USA). VOCs were collected for $48 \mathrm{~h}$, starting at 10:00 h. After collection, Super-Q traps were eluted with $150 \mu \mathrm{l}$ dichloromethane; $5 \mu \mathrm{l}$ of $400 \mathrm{ng}$ of $n$-octane (Sigma-Aldrich) was added to each sample as an internal standard (IS). 
Samples were analyzed on a Hewlett Packard 6890 Series Gas Chromatograph (GC) equipped with a flame ionization detector (FID) (Agilent HP-1 column; Santa Clara, CA, USA): $10 \mathrm{~m} \times 0.53 \mathrm{~mm} \times 2.65 \mu \mathrm{m}$, He as carrier gas: constant flow rate $=5 \mathrm{ml} \mathrm{min}{ }^{-1}$, velocity $=39 \mathrm{~cm} \mathrm{~s}^{-1}$. The program for separation and quantification was set up at $40{ }^{\circ} \mathrm{C}$ initial temperature $(1 \mathrm{~min})$, followed by a temperature ramp of $14{ }^{\circ} \mathrm{C} \min ^{-1}$ to $180{ }^{\circ} \mathrm{C}(2 \mathrm{~min})$, then $40{ }^{\circ} \mathrm{C} \min ^{-1}$ to $200{ }^{\circ} \mathrm{C}$, then $200{ }^{\circ} \mathrm{C}(2 \mathrm{~min})$. Compounds $\left(\mathrm{ng} \mathrm{h}^{-1}\right)$ were quantified based on comparison of peak areas with that of the IS (n-octane). Identification of compounds (for at least one sample per treatment) was performed on a Varian 3400 GC coupled to a Finnigan MAT 8230 Mass Spectrometer (MS) (Supelco MDN-5S column; Bellefonte, PA, USA): $30 \mathrm{~m} \times 0.32 \mathrm{~mm} \times 0.25 \mu \mathrm{m}$. The program was $35^{\circ} \mathrm{C}$ initial temperature ( $1 \mathrm{~min})$, followed by a temperature ramp of $4{ }^{\circ} \mathrm{C} \mathrm{min}{ }^{-1}$ to $170{ }^{\circ} \mathrm{C}$, then $15^{\circ} \mathrm{C} \mathrm{min}{ }^{-1}$ to $280{ }^{\circ} \mathrm{C}$. The MS data were acquired and processed in a Finnigan MAT SS300 data system, and compounds were identified by GC retention index, and comparison of their retention times to those of commercially available compounds and their spectral data to those from the NIST library (Rodriguez-Saona et al. 2009, 2011).

\section{Behavioral response of predators to tridecane}

We identified tridecane (C13) as the major compound emitted by $H$. halys-damaged bean pods and from $H$. halys nymphs and adults (see Results). Likewise, Solomon et al. (2013) and Harris et al. (2015) identified tridecane as the dominant defensive volatile compound secreted from the scent glands of $H$. halys when disturbed. Thus, we conducted experiments to test the attraction of $O$. insidiosus adults to tridecane ( $\geq 99 \%$ purity; Sigma-Aldrich). Choice tests consisted of 1,10 , or $100 \mathrm{ng} / \mu \mathrm{l}$ of tridecane (diluted in hexane; Sigma-Aldrich) versus a control (hexane without tridecane). These concentrations were used to mimic a range of amounts (peaks) emitted from $H$. halys detected by GC (see above). Instead of bean plants, we used artificial plants of similar size $(30 \mathrm{~cm}$ tall) and color (green) to avoid any additional volatile cues. The artificial plants had eight leaves and were placed individually in plastic containers $(250 \mathrm{ml})$ filled with sand. Four artificial plants were placed inside cages (Bugdorm Insect Cage), as described above for natural plants. Two of the plants had a septum (Precision Seal ${ }^{\circledR}$; Sigma-Aldrich) containing $20 \mu \mathrm{l}$ of one of the tridecane concentrations, while the other two had a septum without tridecane. All plants received three $O$. nubilalis egg masses as described above. Fifteen $O$. insidiosus adults (mixed sexes) were released at 10:00 $\mathrm{h}$ in the center of the cage, and their location (numbers on plants) was recorded every hour for $6 \mathrm{~h} \mathrm{day}^{-1}$ and for a total of 3 days. Egg predation was measured as described above. Each choice test was replicated 15 times.

Release rates from tridecane-treated septa $(N=3$ per concentration) were calculated by placing individual septum in 6-ml glass vials (Fisher Scientific Inc, Pittsburg, PA, USA), collecting headspace volatiles from vials as described above for $24 \mathrm{~h}$, and calculating release rates based on a linear regression with known quantities of tridecane; releases rates (mean $\pm \mathrm{SE}$ ) for 1,10 , and $100 \mathrm{ng} / \mu \mathrm{l}$ concentrations were: $1.12 \pm 0.21, \quad 1.79 \pm 0.27$, and $3.78 \pm 0.95 \mathrm{ng} \mathrm{day}^{-1}$, respectively.

\section{Olfactometer assays}

The response of $O$. insidiosus to tridecane was further investigated in a four-arm olfactometer (Volatile Assay Systems; Rensselaer, NY, USA). Three concentrations were tested $(1,10$, and $100 \mathrm{ng} / \mu \mathrm{l})$. The arena consisted of an acrylic chamber $(10 \times 10 \mathrm{~cm})$ that was divided into four zones. A removable plastic chamber $(2 \times 2 \mathrm{~cm})$ was installed at the end of each arm, closed by a cork with a hole covered with gauze for air flow. The top of the arena was covered with a glass plate to prevent insects from escaping. The experiment was conducted in a dark room at $25 \pm 1{ }^{\circ} \mathrm{C}$; a light bulb was positioned on the top of the arena such that the amount of light $(\sim 2500 \mathrm{~lx})$ was similar for all arms. Each treatment was tested by pipetting $20 \mu \mathrm{l}$ of one of the tridecane concentrations onto a piece of Whatman No. 1 filter paper $\left(2.5 \mathrm{~cm}^{2}\right.$; Sigma-Aldrich). The tridecane-treated filter paper was then placed inside the chamber of one of the arms (randomly selected) of the olfactometer; the other arms had filter papers with $20 \mu \mathrm{l}$ of hexane (controls). A single adult $O$. insidiosus (male or female) was released in the center of the arena, and the time that it spent in each arm of the arena was tracked and recorded for 10 min using a video camera (model: acA1300-60gm GigE; Basler, Ahrensburg, Germany) and analyzed with the software Ethovision XT (Noldus Information Technology, Wageningen, Netherlands). Treatments in the olfactometer were replaced, and their position changed, every five insects. The entire arena and the odor chambers were cleaned using soap water and hexane and then dried. Each treatment was replicated 30 times for each gender.

\section{Field experiment}

In June-August 2014, we evaluated the response of Orius spp. to tridecane in peach $(N=4)$, blueberry $(N=4)$, and sunflower $(N=2)$ fields. Both peach (latitude $39^{\circ} 31^{\prime} 36^{\prime \prime} \mathrm{N}$, longitude $75^{\circ} 12^{\prime} 16^{\prime \prime} \mathrm{W}, 37 \mathrm{~m}$ altitude) and sunflower (latitude $39^{\circ} 31^{\prime} 41^{\prime \prime} \mathrm{N}$, longitude $75^{\circ} 12^{\prime} 08^{\prime \prime} \mathrm{W}, 35 \mathrm{~m}$ altitude) fields were located at RAREC (Bridgeton, NJ, USA). The 
blueberry fields were located on an organic farm (latitude $39^{\circ} 39^{\prime} 59^{\prime \prime} \mathrm{N}$, longitude $74^{\circ} 45^{\prime} 13^{\prime \prime} \mathrm{W}, 18 \mathrm{~m}$ altitude) in Hammonton, NJ (USA). Peaches, sunflowers, and blueberries are suitable hosts for $H$. halys feeding and reproduction (Nielsen and Hamilton 2009; Leskey et al. 2012a; Soergel et al. 2015). In each field, the following six treatments were tested in a randomized complete block design: 1, 2, and $3 \mathrm{ml}$ of tridecane, and 3 and $5 \mathrm{ml}$ of MeSA (>99\% purity; SigmaAldrich), and a control. Yellow sticky cards $(23 \mathrm{~cm} \times$ $28 \mathrm{~cm}$ ) (ISCA Technologies; Riverside, CA, USA) were baited with each of the treatments in $3 \mathrm{ml}$ (all except for the $5 \mathrm{ml} \mathrm{MeSA}$ treatment) or $15 \mathrm{ml}$ (for the $5 \mathrm{ml} \mathrm{MeSA}$ treatment) low-density polyethylene vials (Wheaton Science Products; Millville, NJ, USA). One set of traps $(N=6)$ was placed in each of the eight fields (total of 60 traps). Each field was considered a replicate. Traps were placed on plants $\sim 1-1.5 \mathrm{~m}$ from the ground and at least $10 \mathrm{~m}$ apart, and their position rotated clockwise weekly. Traps were replaced every week for a total of five weeks and were examined in the laboratory under a microscope for Orius spp. Release rates were obtained by weighing the vials before and after placing them in the field: release rates (mean $\pm \mathrm{SE})=0.11 \pm 0.01$, $0.26 \pm 0.02, \quad 0.27 \pm 0.04, \quad 0.25 \pm 0.05, \quad 0.49 \pm 0.04 \mathrm{~g}$ $\mathrm{wk}^{-1}$ for the 1,2 , and $3 \mathrm{ml}$ tridecane, and 3 and $5 \mathrm{ml} \mathrm{MeSA}$ treatments, respectively.

In a separate experiment, we evaluated the effects of each of the treatments on egg predation. The experimental design was similar to that described above for sticky traps. The same 10 fields were used in this experiment. Egg masses $(N=4)$ of $O$. nubilalis were glued to a card, as described above for greenhouse experiments, and placed near a vial containing one of the above-mentioned treatments. The cards were then pinned to the underside of leaves, within $20 \mathrm{~cm}$ from the vials. Eggs remained in the field for $24 \mathrm{~h}$, after which they were removed from plants, brought to the laboratory, and checked for egg predation under the microscope. Egg predation was evaluated in the same weeks as it was done for the sticky traps.

\section{Statistical analyses}

All statistical analyses were conducted using the software SPSS $^{\circledR}$ Statistics 22 (SPPS Inc; Chicago, IL, USA). Data on the number of $O$. insidiosus adults on plants in greenhouse cages were analyzed by general linear model (GLM), followed by Tukey's HSD tests $(\alpha=0.05)$. Greenhouse data for multiple observations were summed for each treatment prior to analysis. The same GLM analysis was used to compare tridecane emissions among treatments. An independent-sample $t$ test was used to compare egg predation and attraction of $O$. insidiosus to tridecane-baited artificial plants versus unbaited plants. The same test was used to compare the time spent by males and females in the arms containing different tridecane concentrations in the olfactometer bioassays. Total number of Orius spp. on traps and percentage of egg predation on blueberry, sunflower, and peach fields were analyzed by repeated-measures analysis of variance (ANOVA), with treatment (fixed effect), crop (fixed effect), and time of sampling (week) (random effect), as well as all possible interactions, as independent variables. A significant ANOVA was followed by Tukey's HSD test ( $\alpha=0.05$ ). To establish normality, mean number of Orius spp. on traps were $\ln (x+0.5)$ transformed prior to analysis. Percent data were arcsine square-root-transformed prior to analysis. The results presented correspond to the original (untransformed) data.

\section{Results}

\section{Behavioral response of predators to infested plants}

The presence of $H$. halys feeding damage and prey (sentinel eggs) on bean pods affected $O$. insidiosus attraction (significant damage $\times$ prey interaction; $F=5.52 ; d f=3$, 8; $P=0.047$ ), indicating that the combination of both $H$. halys feeding damage and presence of prey attracted more $O$. insidiosus. In fact, there were significantly more $O$. insidiosus adults on bean plants damaged by $H$. halys in the presence of eggs than on damaged plants without prey $(P<0.05)$ (Fig. 1a). There was, however, no effect of $H$. halys feeding damage alone $(F=0.394 ; d f=1,8$; $P=0.548)$ or an effect of prey alone $(F=2.433 ; d f=1$, $8 ; P=0.157)$ on $O$. insidiosus attraction.

Although there were $\sim 2$ times more $O$. insidiosus adults on damaged plants with prey as compared with undamaged plants with prey, this difference in attraction did not lead to an increase in egg predation $(F=1.96 ; d f=1,4$; $P=0.24)$. In fact, numerically, there was $\sim 6 \times$ lower percent predation of eggs on damaged compared with undamaged plants (Fig. 1b).

\section{Volatile collection and analysis}

We collected volatiles to understand the mechanisms behind $O$. insidiosus attraction to plant-prey associations. Halyomorpha halys nymphs and adults (mixed sexes), as well as bean pods damaged by nymphs and adults of $H$. halys, consistently emitted high amounts of tridecane [retention times of tridecane from our chromatograms deviated from the standard compound by \pm 0.15 (SD) min, and matched by $>95 \%$ the library mass spectrum for tridecane] (Fig. 2). However, tridecane emissions varied significantly among treatments $(F=13.21 ; d f=6,17 ; P<0.001)$ (Table 1). Bean pods damaged by $H$. halys adults and 

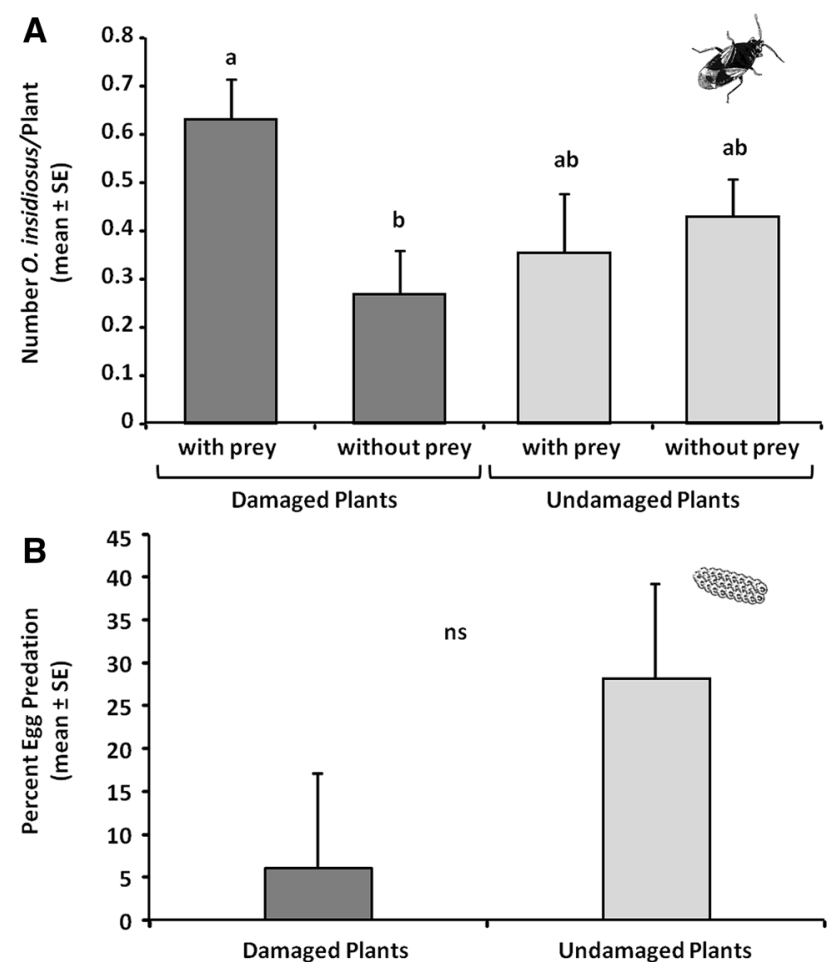

Fig. 1 Attraction of the minute pirate bug, Orius insidiosus, to bean pods previously damaged by Halyomorpha halys and undamaged bean pods in the presence or absence of prey (Ostrinia nubilalis egg masses) (a). Amount of egg predation on damaged and undamaged bean plants (b). Means with different letters are significantly different (Tukey's HSD test; $P \leq 0.05$ ); $n s$ no significant differences between treatments

nymphs emitted higher amounts of tridecane compared with undamaged and artificially damaged bean pods (Table 1), indicating that volatile emissions were elevated by insect herbivory. In addition, nymphs produced significantly higher quantities of tridecane than adults (Table 1). Besides tridecane, no notable differences were observed in the emissions of other $H$. halys-bean-associated volatiles (see Fig. 2) and, thus, are not presented here.

\section{Behavioral response of predators to tridecane}

Choice experiments were conducted to investigate the response of $O$. insidiosus to tridecane. Orius insidiosus adults were $\sim 60 \%$ more attracted to artificial plants baited with tridecane at all concentrations tested as compared with unbaited artificial plants (controls) $(1 \mathrm{ng} / \mu \mathrm{l}, t=4.47$, $d f=14, \quad P=0.003 ; \quad 10 \mathrm{ng} / \mu \mathrm{l}, \quad t=3.79, \quad d f=14$, $P=0.001 ; \quad 100 \mathrm{ng} / \mu \mathrm{l}, \quad t=6.51, \quad d f=14, \quad P<0.001)$ (Fig. 3a).

Although tridecane at the two lower concentrations (1 and $10 \mathrm{ng} / \mu \mathrm{l}$ ) attracted more $O$. insidiosus to artificial plants, we found no differences on egg predation between tridecane-baited and unbaited plants for these concentrations
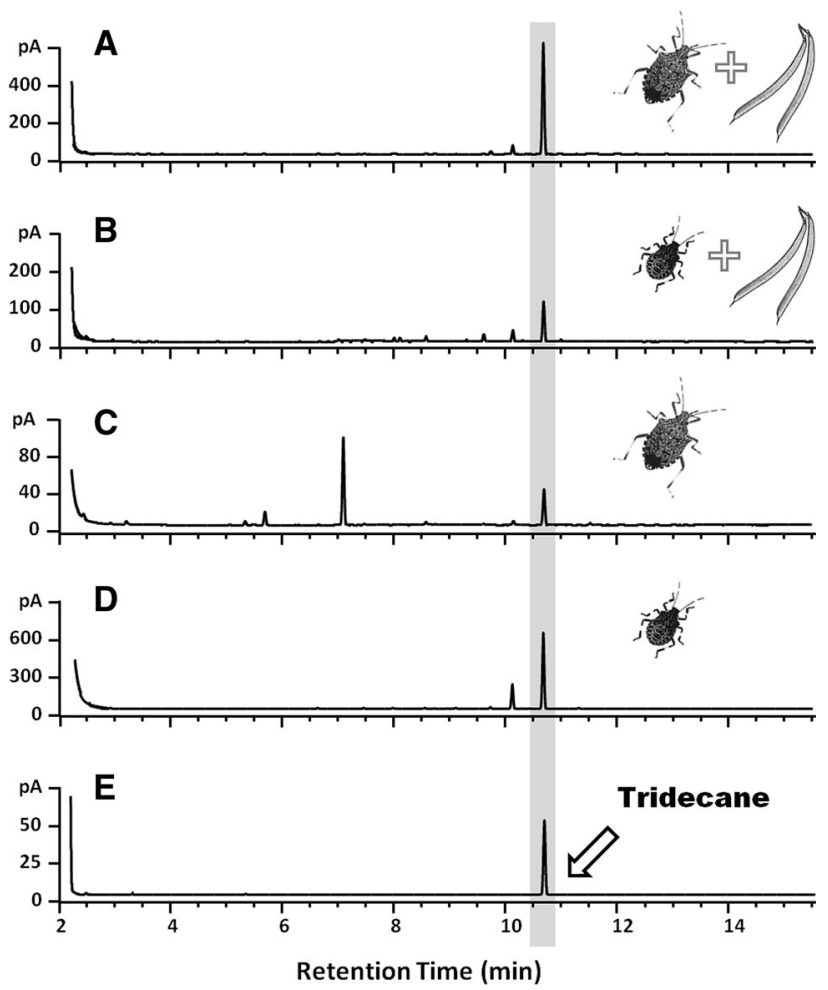

Fig. 2 Typical chromatograms of volatiles collected from a bean pods damaged by Halyomorpha halys adults, $\mathbf{b}$ bean pods damaged by $H$. halys nymphs, c adults only, and d nymphs only. Chromatogram (e) represents the tridecane standard

$(1 \mathrm{ng} / \mu \mathrm{l}: t=1.50, d f=14, P=0.086 ; 10 \mathrm{ng} / \mu \mathrm{l}: t=0.64$, $d f=14, \quad P=0.272$ ) (Fig. 3b). There was, however, $1.8 \times$ higher predation of eggs in the tridecane treatment at $100 \mathrm{ng} / \mu \mathrm{l}$ as compared with the control $(t=2.26, d f=14$, $P=0.027$ ) (Fig. 3b).

\section{Olfactometer assays}

To better understand the behavioral response of $O$. insidiosus toward tridecane, we recorded male and female behaviors toward tridecane in a four-arm olfactometer. Orius insidiosus females spent most of their time $(>30 \%)$ on the tridecane treatment at the highest concentration tested as compared with the control treatments $(100 \mathrm{ng} / \mu \mathrm{l}$, $t=2.37, d f=1, P=0.021$ ) (Fig. 4a). In contrast, $O$. insidiosus females spent significantly more time on the control treatment than the tridecane treatment at the lowest concentration $(1 \mathrm{ng} / \mu \mathrm{l}, t=-2.310, d f=1, P=0.024)$ (Fig. 4a).

Orius insidiosus males spent most of their time ( $>30 \%)$ on both the $10 \mathrm{ng} / \mu \mathrm{l}(t=2.502, d f=1, P=0.015)$ and $100 \mathrm{ng} / \mu \mathrm{l}(t=2.631, d f=1, P=0.011)$ tridecane treatments (Fig. 4b), demonstrating that both concentrations attracted and arrested males. 
Table 1 Amount of tridecane collected from nymphs and adults of the brown marmorated stink bug, Halyomorpha halys, and from $H$. halys-damaged bean pods, mechanically damaged bean pods, bean pods alone, and controls (no insects and plants)

\begin{tabular}{llcl}
\hline Treatments & $N$ & $\begin{array}{l}\text { Tridecane }(\mathrm{ng} / \mathrm{h})^{\mathrm{a}} \\
(\text { mean } \pm \text { SE) }\end{array}$ & \\
\hline Feeding damage by 5 adults of $H$. halys & 6 & $1177.68 \pm 780.63$ & $\mathrm{ab}$ \\
Feeding damage by 5 nymphs of H. halys & 3 & $224.53 \pm 68.93$ & $\mathrm{ab}$ \\
Adults (5) of $H$. Halys & 4 & $30.93 \pm 6.71$ & $\mathrm{bc}$ \\
Nymphs (5) of H. Halys & 4 & $1579.14 \pm 1067.34$ & $\mathrm{a}$ \\
Mechanical damage & 3 & $6.01 \pm 2.23$ & $\mathrm{c}$ \\
Undamaged bean pods & 5 & $10.18 \pm 0.94$ & $\mathrm{bc}$ \\
Control & 3 & $0.00 \pm 0.00$ & $\mathrm{c}$ \\
\hline
\end{tabular}

a Means with different letters are significantly different (Tukey's HSD test; $P \leq 0.05$ )
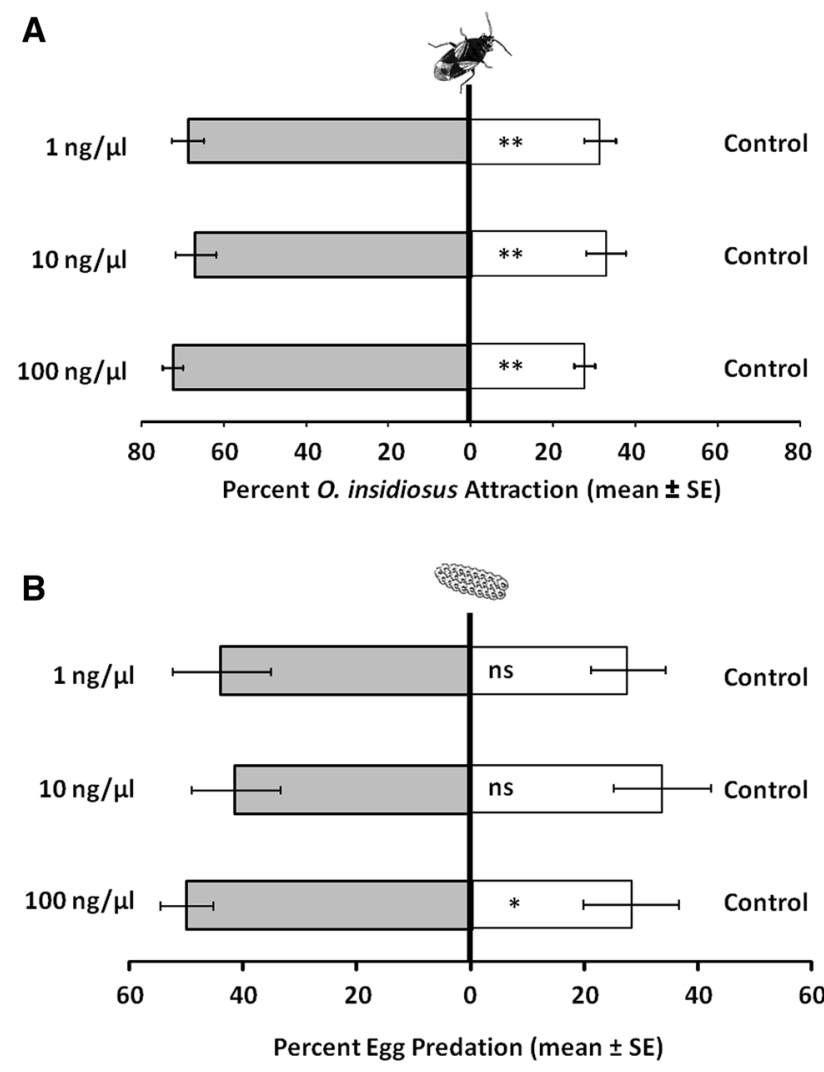

Fig. 3 Attraction of Orius insidiosus to tridecane in choice tests (a). Choices were given between artificial plants baited with one of three different concentrations of tridecane versus unbaited control plants (without tridecane) in greenhouse cage experiments. Amount of egg predation on tridecane-baited and unbaited plants (b). Asterisks indicate significant differences $(t$ tests; $* * P \leq 0.01$, $* 0.01<P \leq 0.05) ; n s$ no significant differences between treatments. $N=15$ replicates per choice test

\section{Field experiments}

Field experiments were conducted to test whether tridecane affect $O$. insidiosus attraction in three cropping systems: sunflowers, blueberries, and peaches. Tridecane-baited traps attracted Orius spp. (significant treatment effect; Table 2A): We found that traps baited with tridecane,
A

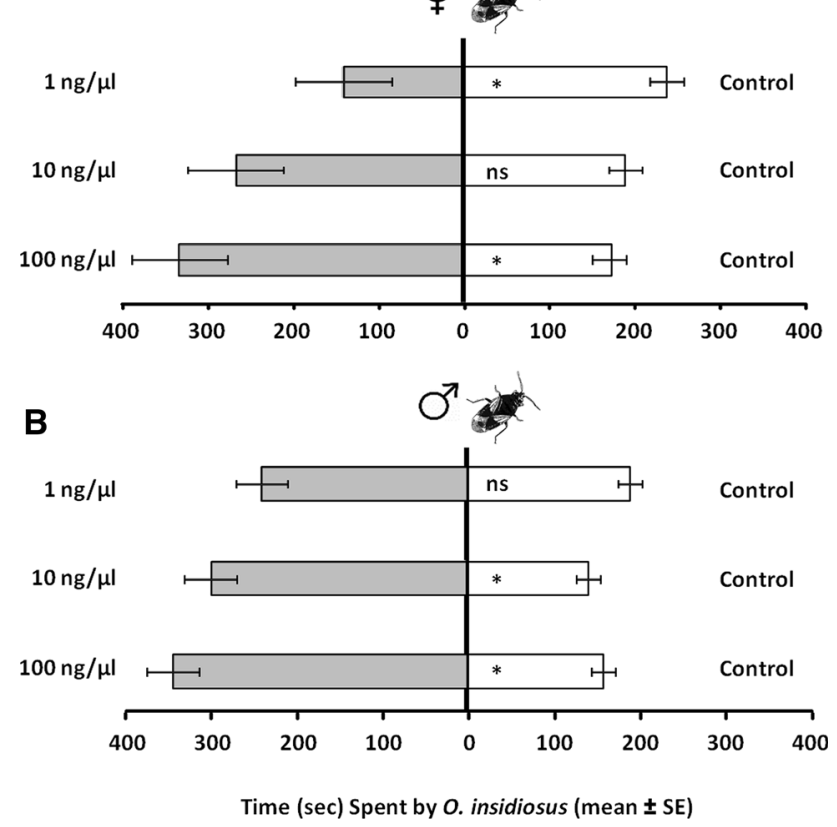

Fig. 4 Response of females (a) and males (b) of Orius insidiosus to tridecane in four-arm olfactometer bioassays. Choice tests consisted of one of three different concentrations of tridecane versus control (without tridecane). Asterisks indicate significant differences ( $t$ tests; $* P<0.05)$; $n s$ not significant. $N=30$ replicates per choice test

particularly at the dose of $2 \mathrm{ml}$, attracted $>2.5 \times$ more Orius spp. as compared with the unbaited control traps (Fig. 5a). Crop was also significant, with sunflower fields having significantly more Orius spp. [mean weekly counts per trap $=2.92 \pm 0.39(\mathrm{SE})]$ than blueberry $(0.48 \pm 0.07)$ and peach $(0.51 \pm 0.09)$ fields (Table $2 \mathrm{~A})$. However, there were neither treatment-by-crop nor treatment-by-week interaction effects (Table 2A), indicating that the effect of treatment was not influenced by the crop or seasonality. In contrast, MeSA-baited traps did not attract Orius spp. in these cropping systems $(P>0.05)$ (Fig. 5a). There were no other significant 2-way or 3-way interaction effects on Orius spp. trap captures. 
Table 2 Summary of repeated-measures analysis of variance (ANOVA) for the effects of treatment, crop, and time of sampling (week), and their interactions, on the numbers of Orius spp. on semiochemical-baited traps (A) and predation of Ostrinia nubilalis egg masses (B)

\begin{tabular}{lrrr}
\hline Variables & $d f^{\mathrm{e}}$ & \multicolumn{1}{l}{$F$} & \multicolumn{1}{l}{$P^{\mathrm{d}}$} \\
\hline A. Trap counts & & & \\
Treatments $^{\mathrm{a}}$ & 5 & 4.92 & $\mathbf{0 . 0 0 4}$ \\
Crop $^{\mathrm{b}}$ & 2 & 40.67 & $<\mathbf{0 . 0 0 1}$ \\
Week $^{\text {Treatment } \times \text { crop }}$ & 4 & 3.57 & 0.070 \\
Treatment $\times$ week & 10 & 1.69 & 0.116 \\
Crop $\times$ week & 20 & 1.11 & 0.378 \\
Treatment $\times$ crop $\times$ week & 8 & 1.21 & 0.317 \\
B. Predation rate & 40 & 1.44 & 0.053 \\
Treatments & & & \\
Crop & \\
Week & 5 & 1.17 & 0.358 \\
Treatment $\times$ crop & 2 & 1.61 & 0.258 \\
Treatment $\times$ week & 4 & 1.40 & 0.316 \\
Crop $\times$ week & 10 & 0.47 & 0.897 \\
Treatment $\times$ crop $\times$ week & 20 & 1.07 & 0.412 \\
\hline
\end{tabular}

a Treatments consisted of 1,2 , and $3 \mathrm{~mL}$ of tridecane, 3 and $5 \mathrm{~mL}$ of methyl salicylate (MeSA), and control

b Crops were blueberries, sunflowers, and peaches

${ }^{c}$ Error $d f=210$

${ }^{\mathrm{d}}$ Numbers in bold are significant at $\alpha=0.05$

In addition to Orius spp. attraction, we also measured predation of sentinel eggs near baited lures. We found no effect of lure treatment on egg predation (Table 2B; Fig. 5b). We found only a significant crop-by-week interaction (Table 2B); in general, sunflower fields had significantly greater egg predation [mean percent predation $=60.37 \% \pm 4.04 \quad(\mathrm{SE})] \quad$ than blueberries $(45.30 \% \pm 2.37)$, while peaches had intermediate levels of predation $(54.60 \% \pm 3.04)$, but this effect varied by seasonality. There were no other significant 2-way or 3-way interaction effects on egg predation (Table 2B).

\section{Discussion}

This study shows that: (1) bean plants damaged by $H$. halys are attractive to the predaceous minute pirate bug, $O$. insidiosus, when prey are present; however, this attraction did not lead to higher egg predation; (2) tridecane was a major volatile compound emitted by both nymphs and adults of $H$. halys and by $H$. halys-damaged bean pods; (3) synthetic tridecane attracted Orius spp. in greenhouse and field experiments; however, in most instances, it did not affect the predator's consumption of prey eggs; (4) in
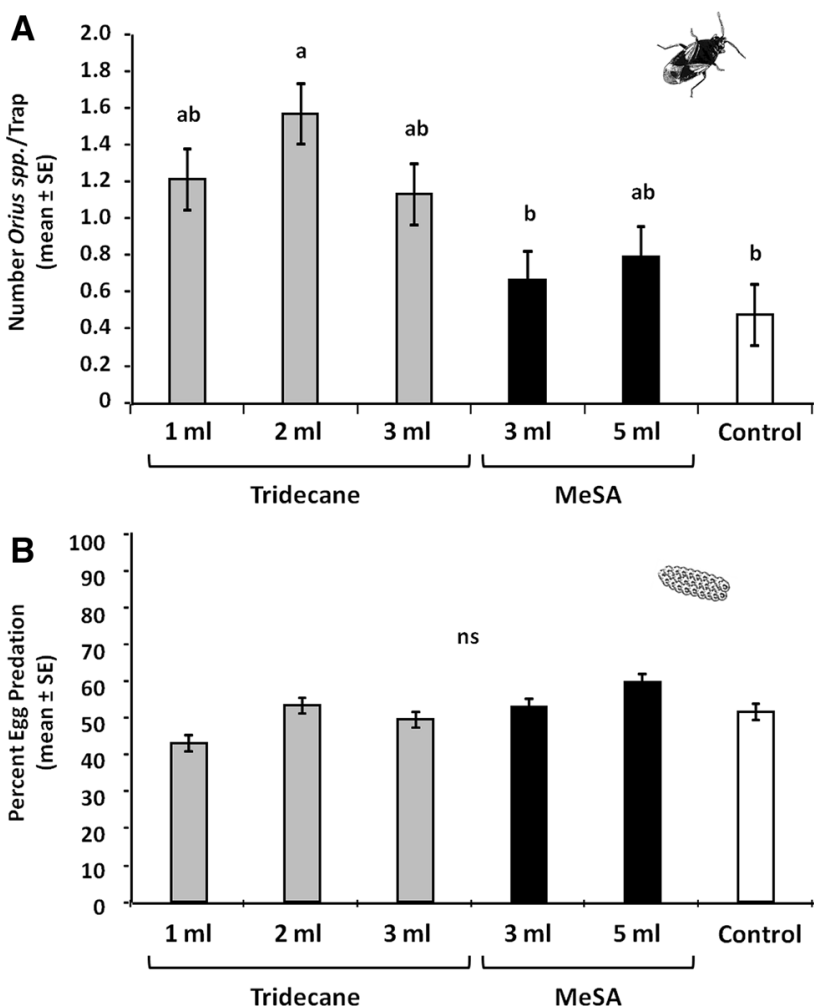

Fig. 5 Attraction of Orius spp. to sticky traps baited with three different doses of tridecane, two doses of methyl salicylate (MeSA), and unbaited controls (a). And, amount of predation on Ostrinia nubilalis egg masses placed near vials containing these same treatments (b). Means with different letters are significantly different (Tukey's HSD test; $P \leq 0.05$ ); $n s$ not significant

olfactometer assays, tridecane arrested $O$. insidiosus behavior, which may explain the lack of correlation between attraction and prey consumption. These results confirm our hypothesis that $O$. insidiosus utilizes volatiles associated with $H$. halys, i.e., tridecane, during prey location.

We found attraction of $O$ insidiosus to $H$. halys-damaged plants with prey. This attraction could be due to either volatiles induced by $H$. halys feeding or volatiles emitted by $H$. halys themselves. Herbivore feeding is known to induce volatiles that can attract natural enemies (Turlings et al. 1990; Thaler 1999; James 2003), and Orius spp. utilize these HIPVs in prey location (James 2003, 2005). In addition, natural enemies can also use aggregation and alarm pheromones produced by stink bugs (Pentatomidae) during prey location (Aldrich et al. 1984, 1989; Aldrich 1995). For example, the egg parasitoid Trissolcus basalis (Wollaston) is attracted to kairomones from Nezara viridula (L.) (Colazza et al. 1999). Orius insidiosus was, however, less attracted to odors from $H$. halys-damaged beans without prey, indicating that this predator might have learned to associate these odors with the presence of a reward, such as eggs (i.e., associative learning). Although 
we expected higher attraction to $H$. halys-damaged plants to lead to greater egg predation, predation of sentinel eggs by $O$. insidiosus was similar on damaged and undamaged plants; see below for a possible explanation. In our studies, we used $O$. nubilalis eggs to assess predation due to their commercial availability and because, as they are generalist predators, we did not expect differences in $O$. insidiosus preference between $O$. nubilalis and $H$. halys eggs as both are acceptable prey items (Musser and Shelton 2003; Morrison et al. 2016); however, this assumption needs to be verified in future studies.

Identifying the volatile cues used by natural enemies in host location is critical for potential manipulation of their behaviors in agro-ecosystems (e.g., Khan et al. 2008). We found that $H$. halys and $H$. halys-bean associations emit high quantities of the alkane hydrocarbon tridecane; however, the origin of tridecane in $H$. halys-bean associations is unknown. Halyomorpha halys is known to produce tridecane (Solomon et al. 2013; Harris et al. 2015); however, Colazza et al. (2004) reported induced emissions of tridecane from bean plants after feeding and oviposition damage by $N$. viridula. Here, we found that feeding by $H$. halys might actively induce tridecane production and emissions because damaged pods emitted more tridecane than mechanically damaged and undamaged pods, suggesting the presence of an insect oral elicitor (Peiffer and Felton 2014). Alternatively, exposed pods might have passively absorbed and released the tridecane emitted from $H$. halys. Moreover, $H$. halys nymphs produced more tridecane than adults. In contrast, Harris et al. (2015) reported 10- and 100-fold higher emissions of tridecane from groups of $H$. halys males as compared with groups of nymphs and females, respectively; we used mixed sexes, which might have been biased toward one of the sexes and may explain these discrepancies. Regardless, our and previous studies (Harris et al. 2015) identified tridecane as the major component of the $H$. halys glandular secretions.

Tridecane attracted $O$. insidiosus in greenhouse and field studies. In addition to $H$. halys, this volatile is produced by several native North American stink bugs species, including Chlorochroa uhleri Say, N. viridula, Erthesina fullo Thunberg, and Thyanta pallidovirens Stål (Aldrich 1988; Kou et al. 1989; Ho and Millar 2001; Fucarino et al. 2004). Thus, it is likely that $O$. insidiosus uses a volatile (kairomone) emitted by $H$. halys that is also common to other stink bug species, such as tridecane, to find its prey. In fact, eggs and nymphs of stink bugs, i.e., N. viridula and Piezodorus guildinni (Westwood) (Tillman 2011; Tillman et al. 2015), including $H$. halys (Morrison et al. 2016), are suitable food items for $O$. insidiosus. Interestingly, both $O$. insidiosus males and females produce pheromones for sex recognition and tridecane is a major male-specific compound in O. insidiosus (Aldrich et al. 2007). Although virgin females are attracted and arrested by volatiles emitted from males, the role of tridecane in $O$. insidiosus sexual behaviors remains unknown. It is also unclear why females spent less time in the tridecane arm of the olfactometer at very low concentrations, unless there is a threshold that indicate the presence of prey at which females respond positively to tridecane; otherwise they may avoid areas emitting low levels of tridecane that are not indicative of prey presence. Orius spp. were not attracted to MeSA in blueberry, sunflower, and peach fields. In a meta-analysis, Rodriguez-Saona et al. (2011) showed that anthocorids as a group respond positively to MeSA. However, Rodriguez-Saona et al. (2011) and Woods et al. (2011) found no behavioral effects of MeSA on Orius spp. in cranberries and hop yards, respectively, indicating that attraction of these predators to MeSA might be crop dependent.

Similar to our earlier findings with plant material, attraction of $O$. insidiosus to synthetic tridecane did not lead to an increase in egg predation when tested in the greenhouse (at the lower concentrations) or in the field, which led us to speculate that $O$. insidiosus was being arrested by tridecane. This speculation was confirmed in olfactometer studies. Although many studies have documented attraction of natural enemies to plant-prey-associated volatiles, fewer studies have observed their behavior after attraction. For example, it is widely known that aphid products, such as sugar-rich honeydew (e.g., Leroy et al. 2014), and aphid alarm pheromones ((E)- $\beta$-farnesene) (e.g., Beale et al. 2006) attract and arrest their natural enemies. In our study, we showed that $O$. insidiosus spends more time near the tridecane odor source, i.e., an arrestant response; particularly males that were more responsive to lower tridecane concentrations than females. These results suggest that tridecane might have distracted this predatory insect in both greenhouse and field experiments by increasing its foraging time in high tridecane-emitting areas and, as a result, limited its ability to consume more prey.

In conclusion, our study highlights the role of a prey $(H$. halys)-related volatile (tridecane) on predator (O. insidiosus) attraction and egg predation. Volatiles from plant-prey associations, such as HIPVs, could be used in augmentative and conservation biological control (Khan et al. 2008). Still, the chemical cues used by natural enemies of $H$. halys in prey location are largely unknown. Tridecane may serve a dual function for $O$. insidiosus, both as a kairomone in prey location and as a pheromone in mate/conspecific location. Unless the goal is to simply retain the predator in specific areas (i.e., provide a refugium), the applicability of tridecane to attract $O$. insidiosus in agricultural systems might be limited at this point because, based on our findings, attraction to tridecane does not necessarily lead to 
increased predation. In addition to tridecane, $H$. halys secretes $(E)$-2-decenal-an alarm compound (Harris et al. 2015). Stink bugs, including $H$. halys (Khrimian et al. 2014; Harris et al. 2015), also produce aggregation pheromones (Aldrich 1988). Further studies are needed to investigate whether these pheromones (i.e., aggregation and alarm pheromones) alone or in combination with HIPVs can be used to manipulate natural enemy behaviors and improve biological control of $H$. halys.

\section{Author contributions}

CR-S, JP, and DFF conceived and designed experiments. DFF and JP conducted experiments and analyzed data. DFF and CR-S wrote the manuscript. GCH and ALN provided insects and field sites. CR-S, GCH, ALN, and ACB provided financial support. All authors read and approved the manuscript.

Acknowledgements Thanks to Big Buck Farms (Hammonton, NJ) for providing blueberry sites for this study and to Robert Holdcraft and Jordano Salamanca for assistance with volatile collections, olfactory assays, and data analysis. We also thank Kris Dahl, Charles Corris, Gabrielle Pintauro, Manuel Chacón-Fuentes, and Caryn Michel for their help with insect colony maintenance and field sampling, and Johnattan Hernández Cumplido, Elvira de Lange, and two anonymous reviewers for critical reading and comments on an earlier draft of the manuscript. Funding for this project was provided by USDA NIFA SCRI Grant \#2011-51181-30937, multi-state hatch projects \#NJ08270 and \#NJ08225, a hatch project \#NJ08192 to CR-S, and a scholarship from the Conselho Nacional de Desenvolvimento Científico e Tecnológico (CNPQ, Brazil) (Process Number: $164869 / 2014-0)$ to DFF.

Funding This study was funded by USDA NIFA SCRI Grant \#201151181-30937 to GCH, ALN, and CR-S, multi-state hatch Projects \#NJ08270 and \#NJ08225 to CR-S, GCH, and ALN, a hatch Project \#NJ08192 to CR-S, and a scholarship from the Conselho Nacional de Desenvolvimento Científico e Tecnológico (CNPQ, Brazil) (Process Number: $164869 / 2014-0)$ to DFF.

\section{Compliance with ethical standards}

Conflict of interest The authors declare that they have no conflict of interest.

Ethical approval All applicable international, national, and/or institutional guidelines for the care and use of animals were followed. This article does not contain studies with humans participants performed by any of the authors.

\section{References}

Aldrich JR (1988) Chemical ecology of the Heteroptera. Annu Rev Entomol 33:211-238

Aldrich JR (1995) Chemical communication in the true bugs and parasitoid exploitation. In: Carde RT, Bell WJ (eds) Chemical ecology of insects. Chapman \& Hall, New York, pp 318-363
Aldrich JR, Kochansky JP, Abrams CB (1984) Attractant for a beneficial insect and its parasitoids: pheromone of the predatory spined soldier bug, Podisus maculiventris (Hemiptera: Pentatomidae). Environ Entomol 13:1031-1036

Aldrich JR, Lusby WR, Marron BE, Nicolaou KC, Hoffmann MP, Wilson LT (1989) Pheromone blends of green stink bugs and possible parasitoid selection. Naturwissenschaften 76:173-175

Aldrich JR, Oliver JE, Shifflet T, Smith CL, Dively GP (2007) Semiochemical investigations of the insidiosus flower bug, Orius insidiosus (Say). J Chem Ecol 33:1477-1493

Andow DA (1990) Characterization of predation on egg masses of Ostrinia nubilalis (Lepidoptera: Pyralidae). Ann Entomol Soc Am 83:482-486

Beale MH, Birkett MA, Bruce TJA, Chamberlain K, Field LM, Huttly AK, Martin JL, Parker R, Phillips AL, Pickett JA, Prosser IM, Shewry PR, Smart LE, Wadhams LJ, Woodcock CM, Zhang Y (2006) Aphid alarm pheromone produced by transgenic plants affects aphid and parasitoid behavior. Proc Natl Acad Sci 103:10509-10513

Biddinger D, Tooker J, Surcica A, Krawczyk G (2012) Survey of native biocontrol agents of the brown marmorated stink bug in Pennsylvania fruit orchards and adjacent habitat. Pa Fruit News 43:47-54

Chabaane Y, Laplanche D, Turlings TCJ, Desurmont GA (2015) Impact of exotic insect herbivores on native tritrophic interactions: a case study of the African cotton leafworm, Spodoptera littoralis and insects associated with the field mustard Brassica rapa. J Ecol 103:109-117

Colautti RI, Ricciardi A, Grigorovich IA, MacIsaac HJ (2004) Is invasion success explained by the enemy release hypothesis? Ecol Lett 7:721-733

Colazza S, Salerno G, Wajnberg E (1999) Volatile and contact chemicals released by Nezara viridula (Heteroptera: Pentatomidae) have a kairomonal effect on the egg parasitoid Trissolcus basalis (Hymenoptera: Scelinidae). Biol Control 16:310-317

Colazza S, McElfresh JS, Millar JG (2004) Identification of volatiles synomones, induced by Nezara viridula feeding and oviposition on bean spp., that attract the egg parasitoid Trissolcus basalis. J Chem Ecol 30:945-964

Colazza S, Cusumano A, Giudice DL, Peri E (2014) Chemoorientation responses in hymenopteran parasitoids induced by substrate-borne semiochemicals. BioControl 59:1-17

De Boer JG, Dicke M (2004) The role of methyl salicylate in prey searching behavior of the predatory mite Phytoseiulus persimilis. J Chem Ecol 30:255-271

De Moraes CM, Lewis WJ, Paré PW, Alborn HT, Tumlonson JH, Paré PW (1998) Herbivore-infested plants selectively attract parasitoids. Nature 393:570-573

Desurmont GA, Harvey J, Van Dam NM, Cristescu SM, Schiestl FP, Cozzolino S, Anderson P, Larsson MC, Kindlmann P, Danner H, Turlings TCJ (2014) Alien interference: disruption of infochemical networks by invasive insect herbivores. Plant Cell Environ 37:1854-1865

Fucarino A, Millar JG, McElfresh JS, Colazza S (2004) Chemical and physical signals mediating conspecific and heterospecific aggregation behavior of first instar stink bugs. J Chem Ecol 30:1257-1269

Gadino AN, Walton VM, Lee JC (2012) Evaluation of methyl salicylate lures on populations of Typhlodromus pyri (Acari: Phytoseiidae) and other natural enemies in western Oregon vineyards. Biol Control 63:48-55

Hansen EA, Hansen EA, Funderburk JE, Reitz SR, Ramachandran S, Eger JE, McAuslane H (2003) Within-plant distribution of Frankliniella species (Thysanoptera: Thripidae) and Orius insidiosus (Heteroptera: Anthocoridae) in field pepper. Environ Entomol 32:1035-1044 
Harris C, Abubeker S, Yu M, Leskey T, Zhang A (2015) Semiochemical production and laboratory behavior response of the brown marmorated stink bug, Halyomorpha halys. PLoS ONE 10:e0140876

Harwood J, Yoo H, Greenstone M, Rowley D, O’Neil R (2009) Differential impact of adults and nymphs of a generalist predator on an exotic invasive pest demonstrated by molecular gutcontent analysis. Biol Invasions 11:895-903

Herring JL (1966) The genus Orius of the western hemisphere (Hemiptera: Anthocoridae). Ann Entomol Soc Am 59:1093-1109

Ho HY, Millar JG (2001) Compounds in metathoracic glands of adults and dorsal abdominal glands of nymphs of the stink bugs, Chlorochroa uhleri, C. sayi, and C. ligata (Hemiptera: Pentatomidae). Zool Stud 40:193-198

Hoebeke ER, Carter ME (2003) Halyomorpha halys (Stål) (Heteroptera: Pentatomidae): a polyphagous plant pest from Asia newly detected in North America. Proc Entomol Soc Wash 105:225-237

Iglinsky W, Rainwater CF (1950) Orius insidiosus, an enemy of a spider mite on cotton. J Econ Entomol 43:567-568

James DG (2003) Synthetic herbivore-induced plant volatiles as field attractants for beneficial insects. Environ Entomol 32:977-982

James DG (2005) Further field evaluation of synthetic herbivoreinduced plan volatiles as attractants for beneficial insects. J Chem Ecol 31:481-495

James DG, Price TS (2004) Field-testing of methyl salicylate for recruitment and retention of beneficial insects in grapes and hops. J Chem Ecol 30:1613-1628

Keane RM, Crawley MJ (2002) Exotic plant invasions and the enemy release hypothesis. Trends Ecol Evol 17:164-170

Kelly JL, Hagler JR, Kaplan I (2014) Semiochemical lures reduce emigration and enhance pest control services in open-field predator augmentation. Biol Control 71:70-77

Khan ZR, James DG, Midega CAO, Pickett JA (2008) Chemical ecology and conservation biological control. Biol Control 45:210-224

Khrimian A, Zhang A, Weber DC, Ho H-Y, Aldrich JR, Vermillion KE, Siegler MA, Shirali S, Guzman F, Leskey TC (2014) Discovery of the aggregation pheromone of the brown marmorated stink bug (Halyomorpha halys) through the creation of stereoisomeric libraries of 1-bisabolen-3-ols. J Nat Prod 77:1708-1717

Kou R, Tang DS, Chow YS (1989) Alarm pheromone of pentatomid bug, Erthesina fullo Thunberg (Hemiptera: Pentatomidae). J Chem Ecol 15:2695-2702

Kuhar TP, Kamminga KL, Whalen J, Dively GP, Brust G, Hooks CRR, Hamilton G, Herbert DA (2012) The pest potential of brown marmorated stink bug on vegetable crops. Plant Health Prog. doi:10.1094/PHP-2012-0523-01-BR

Lattin JD (1990) Bionomics of the Anthocoridae. Annu Rev Entomol 44:207-231

Leroy PD, Almohamad R, Attia S, Capella Q, Verheggen FJ, Haubruge E, Francis F (2014) Aphid honeydew: an arrestant and a contact kairomone for Episyrphus balteatus (Diptera: Syrphidae) larvae and adults. Eur J Entomol 111:237-242

Leskey TC, Hamilton GC, Nielsen AL, Polk DF, Rodriguez-Saona C, Bergh CJ, Herbert AD, Kuhar TP, Pfeiffer D, Dively GP, Hooks CRR, Raupp MJ, Shrewsbury PM, Krawczyk G, Shearer PW, Whalen J, Koplinka-Loehr C, Myers E, Inkley D, Hoelmer KA, Lee DH, Wright SE (2012a) Pest status of the brown marmorated stink bug, Halyomorpha halys in the USA. Outlooks Pest Manag 23:218-226

Leskey TC, Short BD, Butler BR, Wright SE (2012b) Impact of the invasive brown marmorated stink bug, Halyomorpha halys
(Stål), in Mid-Atlantic tree fruit orchards in the United States: case studies of commercial management. Psyche 2012:1-14

Morrison WRIII, Mathews CR, Leskey TC (2016) Frequency, efficiency, and physical characteristics of predation by generalist predators of brown marmorated stink bug (Hemiptera: Pentatomidae) eggs. Biol Control 97:120-130

Musser FR, Shelton AM (2003) Predation of Ostrinia nubilalis (Lepidoptera: Crambidae) eggs in sweet corn by generalist predators and the impact of alternative foods. Environ Entomol 32:1131-1138

Nielsen AL, Hamilton GC (2009) Life history of the invasive species Halyomorpha halys (Hemiptera: Pentatomidae) in northeastern United States. Ann Entomol Soc Am 102:608-616

Ninkovic V, Al Abassi S, Pettersson J (2001) The influence of aphidinduced plant volatiles on ladybird beetle searching behavior. Biol Control 21:191-195

Northeastern IPM Center (2016) Where is BMSB? http://www. stopbmsb.org/where-is-bmsb/. Accessed 15 Oct 2016

Osekre EA, Wright DL, Marois JJ, Mailhot DJ (2008) Predator-prey interactions between Orius insidiosus (Heteroptera: Anthocoridae) and Frankliniella tritici (Thysanoptera: Thripidae) in cotton blooms. J Cotton Sci 201:195-201

Peiffer M, Felton GW (2014) Insights into the saliva of the brown marmorated stink bug Halyomorpha halys (Hemiptera: Pentatomidae). PLoS ONE 9(2):e88483

Pimentel D, Zuniga R, Morrison D (2005) Update on the environmental and economic costs associated with alien-invasive species in the United States. Ecol Econ 52:273-288

Reddy GVP, Holopainen JK, Guerrero A (2002) Olfactory responses of Plutella xylostella natural enemies to host pheromone, larval frass, and green leaf cabbage volatiles. J Chem Ecol 28:131-143

Reid CD, Lampman RL (1989) Olfactory responses of Orius insidiosus (Hemiptera: Anthocoridae) to volatiles of corn silks. J Chem Ecol 15:1109-1115

Rice KB, Bergh CJ, Bergmann EJ, Biddinger DJ, Dieckhoff C, Dively G, Fraser H, Gariepy T, Hamilton G, Haye T, Herbert A, Hoelmer K, Hooks CR, Jones A, Krawczyk G, Kuhar T, Martinson H, Mitchell W, Nielsen AL, Pfeiffer DG, Raupp MJ, Rodriguez-Saona C, Shearer P, Shrewsbury P, Venugopal PD, Whalen J, Wiman NG, Leskey TC, Tooker JF (2014) Biology, ecology, and management of brown marmorated stink bug (Hemiptera: Pentatomidae). J Integr Pest Manag 5:1-13

Rodriguez-Saona CR, Rodriguez-Saona LE, Frost CJ (2009) Herbivoreinduced volatiles in the perennial shrub, Vaccinium corymbosum, and their role in inter-branch signaling. J Chem Ecol 35:163-175

Rodriguez-Saona C, Kaplan I, Braasch J, Chinnasamy D, Williams L (2011) Field responses of predaceous arthropods to methyl salicylate: a meta-analysis and case study in cranberries. Biol Control 59:294-303

Rodriguez-Saona C, Blaauw BR, Isaacs R (2012) Manipulation of natural enemies in agroecosystems habitat and semiochemicals for sustainable insect pest control. In: Soloneski S (ed) Integrated pest management and pest control-current and future tactics. InTech, Rijeka, pp 89-126. doi:10.5772/30375

Shipp JL, Ramakers PMJ (2004) Biological control of thrips on vegetable crops. In: Heinz KM, Van Driesche RG, Parella MP (eds) Biocontrol in protected culture. Ball Publishing, Batavia, pp 265-276

Soergel DC, Ostiguy N, Fleischer SJ, Troyer RR, Rajotte EG, Krawczyk G (2015) Sunflower as a potential trap crop of Halyomorpha halys (Hemiptera: Pentatomidae) in pepper fields. Environ Entomol 44:1581-1589

Solomon D, Dutcher D, Raymond T (2013) Characterization of Halyomorpha halys (brown marmorated stink bug) biogenic volatile organic compound emissions and their role in secondary 
organic aerosol formation. J Air Waste Manag Assoc 63:1264-1269

Teerling CR, Gillespie DR, Borden JH (1993) Utilization of western flower thrips alarm pheromone as a prey-finding kairomone by predators. Can Entomol 125:431-437

Thaler JS (1999) Jasmonate-inducible plant defences cause increased parasitism of herbivores. Nature 399:686-688

Tholl D, Röse USR (2006) Detection and identification of floral scent compounds. In: Dudareva N, Pichersky E (eds) The biology of floral scent. CRC Press, New York, pp 3-25

Tillman PG (2011) Natural biological control of stink bug (Heteroptera: Pentatomidae) eggs in corn, peanut, and cotton farmscapes in Georgia. Environ Entomol 40:303-314

Tillman PG, Greenstone MH, Hu JS (2015) Predation of stink bugs (Hemiptera: Pentatomidae) by a complex of predators in cotton and adjoining soybean habitats in Georgia, USA. Fla Entomol 98:1114-1126

Turlings TC, Tumlinson JH, Lewis WJ (1990) Exploitation of herbivore-induced plant odors by host-seeking parasitic wasps. Science 250:1251-1253
Van Den Boom CEM, Van Beek TA, Posthumus MA, De Groot A, Dicke M (2004) Qualitative and quantitative variation among volatile profiles induced by Tetranychus urticae feeding on plants from various families. J Chem Ecol 30:69-89

Woods JL, James DG, Lee JC, Gent DH (2011) Evaluation of airborne methyl salicylate for improved conservation biological control of two-spotted spider mite and hop aphid in Oregon hop yards. Exp Appl Acarol 55:401-416

Xu J, Fonseca DM, Hamilton GC, Hoelmer KA, Nielsen AL (2014) Tracing the origin of US brown marmorated stink bugs, Halyomorpha halys. Biol Invasions 16:153-166

Yu H, Zhang Y, Wu K, Gao XW, Guo YY (2008) Field-testing of synthetic herbivore-induced plant volatiles as attractants for beneficial insects. Environ Entomol 37:1410-1415

Zhu J, Park KC (2005) Methyl salicylate, a soybean aphid-induced plant volatile attractive to the predator Coccinella septempunctata. J Chem Ecol 31:1733-1746 